
\title{
25 Research Square \\ Beliefs and Barriers Associated with COVID-19 Vaccination Among the General Population in Saudi Arabia
}

Rania M Magadmi ( $\square$ rmagadmi@kau.edu.sa )

King Abdulaziz University https://orcid.org/0000-0003-0886-4068

Fatemah 0. Kamel

King Abdulaziz University

\section{Research article}

Keywords: COVID-19, Vaccine, Saudi Arabia, Vaccine hesitancy, COVID-19 vaccine acceptance

Posted Date: August 18th, 2020

DOI: https://doi.org/10.21203/rs.3.rs-48955/v1

License: (c) (i) This work is licensed under a Creative Commons Attribution 4.0 International License.

Read Full License

Version of Record: A version of this preprint was published at BMC Public Health on July $21 \mathrm{st}, 2021$. See the published version at https://doi.org/10.1186/s12889-021-11501-5. 


\section{Abstract}

Background: Developing a vaccine against COVID-19 is considered a key strategy to end the pandemic. However, public acceptance is reliant on beliefs and perception toward the vaccine. Therefore, the study aimed to assess the beliefs and barriers associated with COVID-19 vaccination among the Saudi population.

Methods: An online self-administered questionnaire was distributed across the main regions of Saudi Arabia on May 2020. The questionnaire addressed the socio-demographic variables, beliefs toward COVID-19 vaccination, and potential barriers that may prevent participants from being vaccinated. The association between COVID-19 vaccine acceptance and sociodemographic variables were analyzed. Logistic regression analysis was used to identify the predicting variables of vaccine acceptance.

Results: Out of 3,101 participants, $44.7 \%$ are accepting of COVID-19 vaccination if available, whereas $55.3 \%$ admitted hesitancy. Younger, male, with secondary education, history of taking previous seasonal influenza vaccine, and positive belief toward COVID-19 vaccination are more likely to accept. The study found that concerns about side effects were the key barrier for vaccine acceptance. Furthermore, the majority of refusers will accept the vaccine if additional studies confirmed safety and effectiveness.

Conclusion: Results can be utilized in planning vaccination campaigns while waiting for vaccine development.

\section{Introduction}

The coronavirus disease-19 (COVID-19) is highly contagious and caused by severe acute respiratory syndrome coronavirus 2 (SARS-CoV-2) [1]. On 30 January 2020, the World Health Organization (WHO) declared an outbreak of a public health emergency of international concern [2]. During the first 6 months, more than 10 million COVID-19 cases were confirmed worldwide, out of which more than 20 thousand were in Saudi Arabia [3]. Although none of the underdevelopment COVID-19 vaccines have reached the market $[4,5]$, vaccination is considered the most effective strategy for preventing the pandemic and avoiding complications associated with the disease. However, many studies $[6,7]$ have shown that the decision to take available vaccines is dependent on beliefs and perceptions. Therefore, worldwide concern regarding public acceptance of an eventual vaccine for COVID-19 has been increasing $[8,9]$.

A recently published review [10] demonstrated that vaccine acceptance and hesitancy vary at the global context. In Saudi Arabia, a COVID-19 vaccine is expected to face significant public hesitancy given the current public hesitancy toward seasonal influenza vaccination $[11,12]$. Thus, the study aimed to assess the beliefs of Saudi Arabians toward eventual COVID-19 vaccination and to uncover the barriers associated with vaccination among the general population in Saudi Arabia.

\section{Methods}




\section{Study design}

The study is cross-sectional in nature and was conducted on May 2020. A validated, self-administered electronic questionnaire was distributed online through social networking sites, such as WhatsApp and Twitter. The study targeted potential participants from the main five regions in Saudi Arabia to attain results that would be generalizable across the country. The questionnaire has been designed and developed for the purpose of this study (supplement 1). At the beginning of the questionnaire, the participants were briefly informed about the objective of the study. In addition, the participants were informed of the procedure. Thus, opting to fill out the questionnaire after reading the informative note was considered informed consent. Prior to the main questionnaire, the participants were asked three screening questions to ensure that they meet the inclusion criteria of the purposive sampling strategy (i.e., above 18-year old, a resident of Saudi Arabia, and agreeable to sharing responses).

The study was approved by the Unit of Biomedical Ethics Research Committee at the Faculty of Medicine, King Abdulaziz University (Reference No. 275 - 20) dated May 19, 2020.

\section{Questionnaire}

A pilot study was carried out on 30 participants to assess the validity of the questionnaire. Furthermore, a pretesting of the questionnaire was conducted using the focus group technique. Two research experts independently reviewed all questionnaire items. The final questionnaire consisted of three domains, where the questions aimed to collect data on socio-demographic variables, beliefs toward COVID-19 vaccination, and potential barriers that may prevent participants from being vaccinated, respectively.

The questionnaire was distributed in Arabic and English languages. Translation was performed using the backward-forward method and double-checked by the authors.

\section{Statistical analysis}

Data cleaning and analysis were performed using the Statistical Package for Social Sciences (SPSS) v. 24.0 (IBM Corporation, Armonk, New York, USA). Descriptive statistics including frequencies (n) and percentage (\%) were used to present the demographic data of the participants.

For the second domain, responses were rated from 0 (upper-most limit of negative belief; antivaccination) to 3 (upper-most limit of positive belief; pro-vaccination). The points from each question were summarized to calculate the total score. A total score of $>2$ was considered positive belief, whereas the opposite is true for a total score of $<2$.

Chi-square test was used to assess the significance of the association (contingency) between COVID-19 vaccine acceptance and sociodemographic variables. Logistic regression analysis was used to calculate the odds ratio $(\mathrm{OR})$ and $95 \%$ confidence intervals $(95 \% \mathrm{Cl})$ to identify the predicting variables of vaccine acceptance. A $P$-value $<.05$ was considered statistically significant. 


\section{Results}

\section{Demographic characteristics}

A total of 3,101 participants from five regions in Saudi Arabia were recruited. Table 1 shows that more than half of the participants (53.4\%) were aged $40-59$ years, $58.3 \%$ were female, and the majority (89.7\%) were Saudi. More than two-third (63.9\%) obtained a university degree. Other participants were engaged in jobs with high risk of COVID-19 infection (healthcare workers $=13.3 \%$; food-related professions, such as catering $=0.6 \%$, interaction with foreigners $=2.2 \%$ ). The most and least numbers of participants were derived from the Western and Northern regions, respectively. Only 25\% declared a history of chronic disease. Lastly, approximately $40 \%$ were definite about obtaining the seasonal influenza vaccine. 
Table 1

Sociodemographic characteristics of participants $(n=3,101)$

\begin{tabular}{|c|c|c|c|}
\hline Characteristics & & $\begin{array}{l}\text { Frequency } \\
\text { (n) }\end{array}$ & $\begin{array}{l}\text { Percentage } \\
\text { (\%) }\end{array}$ \\
\hline \multirow[t]{4}{*}{ Age } & $18-29$ & 390 & $12.6 \%$ \\
\hline & $30-39$ & 781 & $25.2 \%$ \\
\hline & $40-59$ & 1,657 & $53.4 \%$ \\
\hline & $>60$ & 273 & $8.8 \%$ \\
\hline \multirow[t]{2}{*}{ Sex } & Men & 1,294 & $41.7 \%$ \\
\hline & Women & 1,807 & $58.3 \%$ \\
\hline \multirow[t]{2}{*}{ Nationality } & Saudi & 2,783 & $89.7 \%$ \\
\hline & Non-Saudi & 318 & $10.3 \%$ \\
\hline \multirow[t]{5}{*}{ Educational level } & Primary & 6 & $0.2 \%$ \\
\hline & Elementary & 24 & $0.8 \%$ \\
\hline & Secondary & 300 & $9.7 \%$ \\
\hline & University & 1,983 & $63.9 \%$ \\
\hline & Higher education & 788 & $25.4 \%$ \\
\hline \multirow[t]{5}{*}{ Occupation } & Healthcare workers & 411 & $13.3 \%$ \\
\hline & Catering & 19 & $0.6 \%$ \\
\hline & Working with foreigners & 68 & $2.2 \%$ \\
\hline & Other jobs & 1,592 & $51.3 \%$ \\
\hline & $\begin{array}{l}\text { Unemployed (including retirees, } \\
\text { students, and housewives) }\end{array}$ & 1,011 & $32.6 \%$ \\
\hline \multirow[t]{5}{*}{ Region } & Western & 1,928 & $62.2 \%$ \\
\hline & Central & 394 & $12.7 \%$ \\
\hline & Eastern & 377 & $12.2 \%$ \\
\hline & Northern & 101 & $3.3 \%$ \\
\hline & Southern & 301 & $9.7 \%$ \\
\hline \multirow{2}{*}{$\begin{array}{l}\text { Do you have any chronic } \\
\text { disease? }\end{array}$} & Yes & 786 & $25.3 \%$ \\
\hline & No & 2,315 & $74.7 \%$ \\
\hline Did you get the seasonal & Yes & 1,366 & $44.1 \%$ \\
\hline
\end{tabular}




\begin{tabular}{|llll|}
\hline \begin{tabular}{l} 
Chfluenzavaccine before? \\
\hline
\end{tabular} & $\begin{array}{l}\text { Frequency } \\
\text { (n) }\end{array}$ & $\begin{array}{l}\text { Percentage } \\
\text { (\%) }\end{array}$ \\
\hline & No & 1,411 & $45.5 \%$ \\
\hline Not sure & 324 & $10.4 \%$ \\
\hline
\end{tabular}

\section{Beliefs toward COVID-19 vaccination}

Table 2 illustrates uncertainty among the participants regarding the safety (55.4\%) and effectiveness (56.1\%) of eventual COVID-19 vaccination whenever available. However, the majority agreed that getting the vaccine is the best means of avoiding the complications of COVID-19 (46\%). In summary, only onethird of the participants showed positive beliefs toward COVID-19 vaccination.

The same pattern of beliefs was found among a high-risk group who was defined on the following criteria: >60 years old, healthcare worker, working with foreigners, working in catering, or having chronic diseases (supplement 2). 
Table 2

Participants' beliefs toward safety of COVID-19 vaccination $(n=3,101)$.

\begin{tabular}{|c|c|c|}
\hline \multicolumn{2}{|l|}{ Beliefs toward COVID-19 vaccination } & \multirow{2}{*}{$\begin{array}{l}\begin{array}{l}\text { All } \\
\text { subjects }\end{array} \\
\text { n (\%) } \\
886 \\
(28.6 \%)\end{array}$} \\
\hline \multirow[t]{3}{*}{ Do you think that COVID-19 vaccination, whenever available, would be safe? } & Yes & \\
\hline & No & $\begin{array}{l}497 \\
(16 \%)\end{array}$ \\
\hline & Not sure & $\begin{array}{l}1,718 \\
(55.4 \%)\end{array}$ \\
\hline \multirow[t]{3}{*}{$\begin{array}{l}\text { Do you think that COVID-19 vaccination, whenever available, would be } \\
\text { effective? }\end{array}$} & Yes & $\begin{array}{l}1,066 \\
(34.4 \%)\end{array}$ \\
\hline & No & $\begin{array}{l}294 \\
(9.5 \%)\end{array}$ \\
\hline & Not sure & $\begin{array}{l}1,741 \\
(56.1 \%)\end{array}$ \\
\hline \multirow[t]{3}{*}{$\begin{array}{l}\text { Do you think that the best way to avoid the complications of COVID-19 is by } \\
\text { being vaccinated? }\end{array}$} & Yes & $\begin{array}{l}1,428 \\
(46 \%)\end{array}$ \\
\hline & No & $\begin{array}{l}867 \\
(28 \%)\end{array}$ \\
\hline & Not sure & $\begin{array}{l}806 \\
(26 \%)\end{array}$ \\
\hline \multirow[t]{2}{*}{ If COVID-19 vaccination is available, are you planning to get it? } & Yes & $\begin{array}{l}1,386 \\
(44.7 \%)\end{array}$ \\
\hline & No & $\begin{array}{l}1,715 \\
(55.3 \%)\end{array}$ \\
\hline \multirow[t]{2}{*}{ Total score for beliefs } & Positive & $\begin{array}{l}1,021 \\
(32.92 \%)\end{array}$ \\
\hline & Negative & $\begin{array}{l}2,080 \\
(67.08 \%)\end{array}$ \\
\hline
\end{tabular}

\section{COVID-19 vaccine acceptance}

Table 3 shows the characteristic of individuals who would accept and refuse COVID-19 vaccination. Out of 3,101 participants, $44.7 \%$ declared that they are planning to be vaccinated. Participants aged less than 30 years were found to be 1.572 times more likely to accept vaccination ( $95 \% \mathrm{Cl}$ : $1.06-2.33)$ compared with those aged $>60$ years. Similarly, participants with secondary or university education were 1.75 (95\% Cl: $1.26-2.44)$ and 1.295 (95\% Cl: $1.06-1.59)$ times more likely to accept vaccination, respectively. Moreover, the male participants were 1.204 times likely to accept vaccination (95\% Cl: 1.01-1.44). 
Table 3

Predicting factors of COVID-19 vaccine acceptance

\begin{tabular}{|c|c|c|c|c|c|c|}
\hline \multirow[t]{2}{*}{ Variable } & & \multicolumn{2}{|c|}{$\begin{array}{l}\text { Planned to obtain } \\
\text { COVID-19 Vaccination }\end{array}$} & \multirow[t]{2}{*}{ OR } & \multirow[t]{2}{*}{$95 \% \mathrm{Cl}$} & \multirow[t]{2}{*}{$P$} \\
\hline & & Yes (\%) & No (\%) & & & \\
\hline Total & & $\begin{array}{l}n=1,386 \\
(44.7 \%)\end{array}$ & $\begin{array}{l}n=1,715 \\
(55.3 \%)\end{array}$ & & & \\
\hline \multirow[t]{4}{*}{ Age } & $18-29$ & $238(61 \%)$ & 152 (39\%) & 1.57 & $1.06-2.33$ & $.024 *$ \\
\hline & $30-39$ & $\begin{array}{l}351 \\
(44.9 \%)\end{array}$ & $\begin{array}{l}430 \\
(55.1 \%)\end{array}$ & 0.9 & $0.63-1.29$ & .566 \\
\hline & $40-59$ & 696 (42\%) & $961(58 \%)$ & 1.01 & $0.76-1.47$ & .736 \\
\hline & $>60$ & $101(37 \%)$ & $172(63 \%)$ & - & - & - \\
\hline \multirow[t]{2}{*}{ Gender } & Male & $\begin{array}{l}626 \\
(48.4 \%)\end{array}$ & $\begin{array}{l}668 \\
(51.6 \%)\end{array}$ & 1.2 & $1.01-1.44$ & $.04^{\star}$ \\
\hline & Female & $\begin{array}{l}760 \\
(42.1 \%)\end{array}$ & $\begin{array}{l}1,047 \\
(57.9 \%)\end{array}$ & - & - & \\
\hline \multirow[t]{2}{*}{ Nationality } & Saudi & $\begin{array}{l}1,241 \\
(44.6 \%)\end{array}$ & $\begin{array}{l}1,542 \\
(55.4 \%)\end{array}$ & 0.94 & $0.72-1.24$ & .67 \\
\hline & Non-Saudi & $\begin{array}{l}145 \\
(45.6 \%)\end{array}$ & $\begin{array}{l}173 \\
(54.4 \%)\end{array}$ & - & - & . \\
\hline \multirow[t]{5}{*}{ Educational level } & Primary & $4(66.7 \%)$ & $2(33.3 \%)$ & 2.89 & $\begin{array}{l}0.46- \\
18.24\end{array}$ & .260 \\
\hline & Elementary & $12(50 \%)$ & $12(50 \%)$ & 2.19 & $0.85-5.62$ & .104 \\
\hline & Secondary & $\begin{array}{l}154 \\
(51.3 \%)\end{array}$ & $\begin{array}{l}146 \\
(48.7 \%)\end{array}$ & 1.75 & $1.26-2.44$ & $.001 *$ \\
\hline & University & $\begin{array}{l}899 \\
(45.3 \%)\end{array}$ & $\begin{array}{l}1,084 \\
(54.7 \%)\end{array}$ & 1.3 & $1.06-1.59$ & $.014^{\star}$ \\
\hline & $\begin{array}{l}\text { Higher } \\
\text { education }\end{array}$ & $\begin{array}{l}317 \\
(40.2 \%)\end{array}$ & $\begin{array}{l}471 \\
(59.8 \%)\end{array}$ & - & - & \\
\hline \multirow[t]{4}{*}{ Occupation } & $\begin{array}{l}\text { Healthcare } \\
\text { workers }\end{array}$ & $\begin{array}{l}194 \\
\text { (47.2\%) }\end{array}$ & $\begin{array}{l}217 \\
(52.8 \%)\end{array}$ & 1.36 & $0.17-1.69$ & .285 \\
\hline & Catering & $6(31.6 \%)$ & $\begin{array}{l}13 \\
(68.4 \%)\end{array}$ & 0.73 & $0.21-2.6$ & .627 \\
\hline & Other jobs & $\begin{array}{l}708 \\
(44.5 \%)\end{array}$ & $\begin{array}{l}884 \\
(55.5 \%)\end{array}$ & 1.15 & $0.61-2.17$ & .670 \\
\hline & Unemployed & $\begin{array}{l}450 \\
(44.5 \%)\end{array}$ & $\begin{array}{l}561 \\
(55.5 \%)\end{array}$ & 0.99 & $0.52-1.89$ & .977 \\
\hline
\end{tabular}




\begin{tabular}{|c|c|c|c|c|c|c|c|}
\hline \multirow[t]{3}{*}{ Variable } & & \multicolumn{2}{|c|}{$\begin{array}{l}\text { Planned to obtain } \\
\text { COVID-19 Vaccination }\end{array}$} & \multirow[t]{2}{*}{ OR } & \multirow{2}{*}{\multicolumn{2}{|c|}{$95 \% \mathrm{Cl}$}} & \multirow[t]{2}{*}{$P$} \\
\hline & & Yes (\%) & No (\%) & & & & \\
\hline & $\begin{array}{l}\text { Working with } \\
\text { foreigners }\end{array}$ & $\begin{array}{l}28 \\
(41.2 \%)\end{array}$ & $\begin{array}{l}40 \\
(58.8 \%)\end{array}$ & - & - & & \\
\hline \multirow[t]{5}{*}{ Region } & Western & $\begin{array}{l}845 \\
(43.8 \%)\end{array}$ & $\begin{array}{l}1,083 \\
(56.2 \%)\end{array}$ & - & - & & - \\
\hline & Central & $\begin{array}{l}165 \\
(41.9 \%)\end{array}$ & $\begin{array}{l}229 \\
(58.1 \%)\end{array}$ & 0.84 & \multicolumn{2}{|c|}{$0.64-1.09$} & .187 \\
\hline & Eastern & $\begin{array}{l}173 \\
(45.9 \%)\end{array}$ & $\begin{array}{l}204 \\
(54.1 \%)\end{array}$ & 1.04 & $\begin{array}{l}0.79- \\
1.37\end{array}$ & .76 & \\
\hline & Northern & $\begin{array}{l}60 \\
(59.4 \%)\end{array}$ & $\begin{array}{l}41 \\
(40.6 \%)\end{array}$ & 1.47 & $\begin{array}{l}0.91- \\
2.39\end{array}$ & .116 & \\
\hline & Southern & $\begin{array}{l}143 \\
(47.5 \%)\end{array}$ & $\begin{array}{l}158 \\
(52.5 \%)\end{array}$ & 1.15 & $\begin{array}{l}0.86- \\
1.53\end{array}$ & .357 & \\
\hline \multirow[t]{2}{*}{$\begin{array}{l}\text { Do you have any chronic } \\
\text { disease? }\end{array}$} & Yes & $346(44 \%)$ & $440(56 \%)$ & 0.95 & $\begin{array}{l}0.78- \\
1.17\end{array}$ & .549 & \\
\hline & No & $\begin{array}{l}1,040 \\
(44.9 \%)\end{array}$ & $\begin{array}{l}1,275 \\
(55.1 \%)\end{array}$ & - & - & - & \\
\hline \multirow[t]{3}{*}{$\begin{array}{l}\text { Did you get the seasonal } \\
\text { influenza vaccine before? }\end{array}$} & Yes & $\begin{array}{l}700 \\
(51.2 \%)\end{array}$ & $\begin{array}{l}666 \\
(48.8 \%)\end{array}$ & 1.59 & $\begin{array}{l}1.19- \\
2.14\end{array}$ & $.002^{\prime}$ & \\
\hline & No & $\begin{array}{l}532 \\
(37.7 \%)\end{array}$ & $\begin{array}{l}879 \\
(62.3 \%)\end{array}$ & 1.02 & $\begin{array}{l}0.76- \\
1.37\end{array}$ & .892 & \\
\hline & Not sure & $\begin{array}{l}154 \\
(47.5 \%)\end{array}$ & $\begin{array}{l}170 \\
(52.5 \%)\end{array}$ & - & - & - & \\
\hline \multirow[t]{2}{*}{ Beliefs } & $\begin{array}{l}\text { Positive } \\
(\mathrm{n}=1,021)\end{array}$ & $\begin{array}{l}806 \\
(78.9 \%)\end{array}$ & $\begin{array}{l}215 \\
(21.1 \%)\end{array}$ & 9.29 & $\begin{array}{l}7.7- \\
11.2\end{array}$ & $.000^{\prime}$ & \\
\hline & $\begin{array}{l}\text { Negative } \\
(\mathrm{n}=2,080)\end{array}$ & $\begin{array}{l}580 \\
(27.9 \%)\end{array}$ & $\begin{array}{l}1,500 \\
(72.1 \%)\end{array}$ & - & - & - & \\
\hline
\end{tabular}

As expected, participants with a history of taking previous seasonal influenza vaccines were 1.594 times more likely to accept COVID-19 vaccination (95\% Cl: 1.19-2.14). A remarkable increase in the likelihood of being vaccinated was observed for those who held positive beliefs. In this case, the participants with positive beliefs toward COVID-19 vaccination were 9.288 times more likely to accept vaccination if available (95\% Cl: 7.72-11.17).

However, Table 3 illustrates that nationalities, occupations, chronic diseases, or residence in regions across Saudi Arabia were unable to predict vaccination behavior ( $P$-value $>0.05)$. 
Table 4 shows the barriers associated with acceptance of COVID-19 vaccination. More than one answer was available for each item; hence, cumulative percentages exceeded $100 \%$. The majority of vaccine refusers were concerned about side effects (80\%). Approximately $25 \%$ lack confidence in the effectiveness of vaccination (23.4\%). One-fifth of the precipitants supported the conspiracy theory surrounding COVID-19, whereas the remainder believed that vaccines are unnecessary because they are strongly compliant with personal hygiene practices and social distancing or because they consider themselves healthy and not at risk.

However, more than two-third of vaccine refusers (63.9\%) indicated that they will agree to be vaccinated if further studies confirmed the safety and effectiveness of COVID-19 vaccination. A total of $44 \%$ of vaccine refusers will agree to vaccination if made compulsory by the government but only $11 \%$ if made compulsory by employers. Furthermore, one-fifth of vaccine refusers will accept vaccination if recommended by physicians. A significant percentage of vaccine refusers $(17.8 \%)$ will not take the vaccine under any of the cited circumstances. 
Table 4

Participants' barriers associated with acceptance of COVID-19 vaccination

\section{Barriers}

Vaccine refusers

$(n=1,715)$

I am concerned about the vaccine's side effects.

$1,371(79.9 \%)$

I don't believe that the vaccine will stop the infection.

$401(23.4 \%)$

COVID-19 vaccination is a conspiracy.

$380(22.2 \%)$

I don't need the vaccine because I do all the right things. I wash my hands and

$372(21.7 \%)$ wear a mask and gloves.

I don't need the vaccine because I'm young and healthy.

$176(10.3 \%)$

I don't like needles.

$38(2.2 \%)$

Other

$275(16 \%)$

Options to encourage future COVID-19 vaccination

If my physician recommended it to me

$353(20.6 \%)$

If I know that more studies showed that the vaccine is safe and effective

$1,096(63.9 \%)$

If it was compulsory by the government $(\mathrm{MOH})$

$754(44 \%)$

If it was mandatory by my job

$203(11.8 \%)$

If my family or friends got vaccinated

$102(5.9 \%)$

If there is a way other than injection

$71(4.1 \%)$

I would not take it in anyway.

$305(17.8 \%)$

Other

$71(4.1 \%)$

\section{Discussion}

Results indicated that the sample population was divided between vaccine acceptance and refusal whenever available. This finding highlights the dilemma of the topic in the Saudi population, where half of the population will accept vaccination. Moreover, the study revealed several key predictors of hesitancy toward COVID-19 vaccination. Older females with high levels of education, no history of influenza vaccine uptake, and negative beliefs toward vaccination were more likely to display hesitation toward COVID-19 vaccination. Notably, being part of a high risk group did not improve the odds of being vaccinated. The most significant predictor of vaccination is holding positive beliefs.

Although studies that assessed hesitancy toward COVID-19 vaccination are limited, the acceptance/ hesitancy rates toward any vaccine are diverse across the world [10]. Correspondingly, the percentage of hesitancy toward COVID-19 vaccination in the present study was twice that of the percentage reported for 
China [8], the USA [13], and Egypt [14]. This result emphasized the fact that further efforts are required in Saudi Arabia to increase the future uptake of COVID-19 vaccination perhaps by improving beliefs over eventual COVID-19 vaccination in particular and vaccination in general.

The most significant predictor for acceptance of COVID-19 vaccination was beliefs. This result is congruent with that of a previous systematic review conducted by Bish et al.[15] to assess the evidence for factors associated with H1N1 vaccine acceptance. The authors reported that participants' beliefs toward $\mathrm{H} 1 \mathrm{~N} 1$ vaccination was strongly associated with the intention to be vaccinated in studies carried out in Turkey, Australia, the United Kingdom, and Malaysia.

Results demonstrated that self-reported influenza vaccine uptake was a positive predictor for the acceptance of eventual COVID-19 vaccination. Similarly, previous studies have shown that the rate of H1N1 vaccine acceptance was higher among participants with a history of uptake of the seasonal influenza vaccine in the USA [16] and France [17]. Of concern, however, the self-reported rate of influenza vaccine is very low across regions in Saudi Arabia. A study carried out in the Western region of Saudi Arabia indicated that only $18.5 \%$ of people received the influenza vaccine in 2015 [18]. The same rate was reported in the Central region of Saudi Arabia in 2011 [19]. Given that COVID-19 is highly contagious with high mortality rates, a significant portion of the population should be vaccinated for the prevention of the disease. However, given the correlation between previous influenza vaccine use and likelihood of accepting COVID-19 vaccination, the current study argued that the Saudi population may experience low rates of vaccination whenever COVID-19 vaccination becomes available.

Male gender was another positive predictor for acceptance of COVID-19 vaccination. This result could be due to the reported high rates of COVID-19-related morbidity and motility among male infected patients [20]. Furthermore, women tend to support conspiracy theories at a higher proportion than men [21], which may be one of the factors that can explain women's higher resistance to vaccination.

Another positive predictor for the acceptance of COVID-19 vaccination was age. Younger participants tended to be more accepting of vaccination in contrast with older participants. The same trend was observed among participants with secondary and university levels of education compared to participants with higher education. A possible explanation is that younger participants are more frustrated with social restrictions and curfews associated with the COVID-19 crisis and would thus be more willing to be vaccinated. At the same time, younger people may be more accustomed and trusting of science and technology in contrast with their older counterparts. At the same time, school suspension may negatively affect the academic performance of school-aged and university participants. Therefore, they are more impatient to bring an end to the situation and thus more accepting of vaccination. Further studies should explore these possibilities as these data can be useful for future vaccination campaigns.

Although a previous study indicated that the majority of Chinese healthcare workers were willing to accept COVID-19 vaccination [8], more than half of Saudi healthcare workers displayed hesitancy toward vaccination. However, hesitancy toward influenza vaccination has been previously reported among Irish [22] and Saudi [23] healthcare workers. At the other end of the spectrum, Dempsey et al.[24] underlined 
the positive influence of healthcare professionals on increasing the uptake of human papillomavirus vaccination among adolescents in a randomized clinical trial. Given these aspects, the finding of the present study regarding the hesitancy of healthcare workers in Saudi Arabia toward COVID-19 vaccination is concerning for the following reasons. First, healthcare workers are at high risk of COVID-19 infection and thus of spreading the disease. Secondly, healthcare workers play a central role in convincing people to be vaccinated. This role will most likely be pivotal in increasing the uptake of COVID-19 vaccination. This tendency indicates that future research should focus on assessing the scale of reluctance toward vaccination among Saudi healthcare workers and on developing and testing interventions that may improve vaccination uptake rates and beliefs among healthcare workers in Saudi Arabia.

As stated by MacDonald [25], factors influencing hesitancy toward vaccination could be related to confidence, complacency, and/or convenience. In the present study, lack of confidence in the safety and effectiveness of vaccination were the main barriers preventing the acceptance of COVID-19 vaccination among the population. The speedy pattern of the development of the prospective COVID-19 vaccines could be one of the reasons behind the lack confidence in vaccination, which is similar to reports on the H1N1 pandemic [26].

Another barrier to COVID-19 vaccination was the COVID-19 conspiracy theory, which has spread very rapidly around the world $[9,27,28]$ via social media platforms, precisely where the study participants were recruited. This scenario may indicate that future studies should use a different sampling population via purposive sampling by first testing the susceptibility potential participants to believe in conspiracy theories.

The widespread conspiracy theory could be due to the people's psychological need to understand the unexpected events associated with the COVID-19 pandemic [29]. Moreover, the conspiracy theory has been reported as a reason as a factor for hesitancy toward vaccination, such as that during the H1N1 pandemic [30] and influenza vaccine among the Saudi population [23].

In agreement with previous research in China [8], the majority of vaccine refusers stated that they require additional research to confirm the safety and effectiveness of vaccination before acceptance. This finding could be explained partially by the fact that majority of the participants in the current study were at the university level. Moreover, the majority of vaccine refusers achieved higher levels of education. Consequently, their background knowledge may contribute to their judgment on the vaccination concept.

Notably, during the H1N1 influenza A pandemic, the public acceptance rate of Americans toward vaccination before its approval was $8.7 \%$ [31]. However, the rate of self-reported vaccination uptake increased to $20 \%$ after a vaccine was introduced to the market [32].

Given that vaccination is the cornerstone of reduced healthcare burden caused by the COVID-19 pandemic, the results of the study can be utilized for planning evidence-based vaccination campaigns while waiting for vaccine development [33]. By enhancing people's beliefs over vaccination and by 
understanding the barriers to acceptance of COVID-19 vaccination will most likely enhance people's acceptance, which may result in a maximized vaccine uptake when it becomes available.

The current study has certain limitations. The study was conducted using an online self-administered questionnaire instead of face-to-face interviews due to the implemented curfew and social distancing restrictions during the COVID-19 pandemic. As a result, reporting bias should be considered. Moreover, the cross-sectional study represents public acceptance and beliefs toward COVID-19 vaccination during the pandemic before the availability of a vaccine. With this notion, people's acceptance and beliefs could be changed with time as reported in other studies on pandemics [16].

Furthermore, disparities were noted across regions with regard to response rate. The highest response rate was noted for the Western region, which is one of the largest in the country. The Makkah, AlMadinah, and Jeddah cities can be found in this region, which are the most affected cities by COVID-19 in Saudi Arabia. This scenario could make people from the region more aware and anxious about topics related to COVID-19. Other factors may have contributed, such as availability of the Internet as well as differences in perception toward the use of social media platforms across regions.

\section{Declarations}

\section{Acknowledgements}

The authors would like to thank all participants who gave their time to fill the questionnaire during COVID19 pandemic. In addition, the authors would like to acknowledge Enago (www.enago.com) for their English language editing service.

\section{Authors contribution}

Idea development and study design: Dr. Rania. Magadmi, Dr.Fatmah O Kamel. Acquiring data: Dr.Fatmah O Kamel, Dr. Rania. Magadmi. Data analysis: Dr.Fatmah O Kamel, Dr. Rania. Magadmi. Drafting the manuscript: Dr. Rania. Magadmi. Final writing up and critical revision of paper: Dr.Fatmah O Kamel. Submission of the manuscript: Dr. Rania. Magadmi. All authors read and approved the final manuscript.

\section{Funding}

This research did not receive any specific grant from funding agencies in the public, commercial, or notfor-profit sectors.

\section{Availability of data}

Data that support the findings in the current study are available from the corresponding author on reasonable request.

\section{Ethics approval and consent to participate}


The study was approved by the Unit of Biomedical Ethics Research Committee at the Faculty of Medicine, King Abdulaziz University (Reference No. 275-20) dated May 19, 2020. At the beginning of the questionnaire, the participants were briefly informed about the objective of the study. In addition, the participants were informed of the procedure. Thus, opting to fill out the questionnaire after reading the informative note was considered informed consent.

\section{Competing interests}

The authors declared that there is no conflict of interest.

\section{References}

1. World Health Organization. WHO Director-General's remarks at the media briefing on 2019-nCoV on 11 February 20202020 [Available from: https://www.who.int/dg/speeches/detail/who-directorgeneral-s-remarks-at-the-media-briefing-on-2019-ncov-on-11-february-2020.

2. World Health Organization. WHO Director-General's statement on IHR Emergency Committee on Novel Coronavirus (2019-nCoV) 2020 [Available from: https://www.who.int/dg/speeches/detail/whodirector-general-s-statement-on-ihr-emergency-committee-on-novel-coronavirus-(2019-ncov)) Accessed 23 July 2020.

3. WHO Coronavirus Disease (COVID-19) Dashboard 2020 [Available from: https://covid19. who.int. Accessed 23 July 2020.

4. Thanh Le T, Andreadakis Z, Kumar A, Gomez Roman R, Tollefsen S, Saville M, et al. The COVID-19 vaccine development landscape. Nat Rev Drug Discov. 2020;19(5):305-6.

5. Schaffer DeRoo S, Pudalov NJ, Fu LY. Planning for a COVID-19 Vaccination Program. Jama. 2020.

6. Larson HJ, de Figueiredo A, Xiahong Z, Schulz WS, Verger P, Johnston IG, et al. The State of Vaccine Confidence 2016: Global Insights Through a 67-Country Survey. EBioMedicine. 2016;12:295-301.

7. Bankamp B, Hickman C, Icenogle JP, Rota PA. Successes and challenges for preventing measles, mumps and rubella by vaccination. Current Opinion in Virology. 2019;34:110-6.

8. Fu C, Wei Z, Pei S, Li S, Sun X, Liu P. Acceptance and preference for COVID-19 vaccination in healthcare workers (HCWs). medRxiv. 2020:2020.04.09.20060103.

9. Khan YH, Mallhi TH, Alotaibi NH, Alzarea Al, Alanazi AS, Tanveer N, et al. Threat of COVID-19 Vaccine Hesitancy in Pakistan: The Need for Measures to Neutralize Misleading Narratives. Am J Trop Med Hyg. 2020.

10. Xiao X, Wong RM. Vaccine hesitancy and perceived behavioral control: A meta-analysis. Vaccine. 2020;38(33):5131-8.

11. Almotairy AM, Sheikh WA, Joraid AAA, Bajwi AA, Alharbi MSF, Al-Dubai SAR. Association between knowledge of influenza vaccine and vaccination status among general population attending primary health care centers in Al-Madinah, Saudi Arabia. Journal of family medicine and primary care. 2019;8(9):2971-4. 
12. Alqahtani AS, Althobaity HM, Al Aboud D, Abdel-Moneim AS. Knowledge and attitudes of Saudi populations regarding seasonal influenza vaccination. Journal of infection and public health. 2017;10(6):897-900.

13. Thunstr^ ${ }^{\wedge}$ L, Ashworth M, Finnoff DC, Newbold SC. Hesitancy Towards a COVID-19 Vaccine and Prospects for Herd Immunity. 2020.

14. Abdelhafiz AS, Mohammed Z, Ibrahim ME, Ziady HH, Alorabi M, Ayyad M, et al. Knowledge, Perceptions, and Attitude of Egyptians Towards the Novel Coronavirus Disease (COVID-19). J Community Health. 2020.

15. Bish A, Yardley L, Nicoll A, Michie S. Factors associated with uptake of vaccination against pandemic influenza: a systematic review. Vaccine. 2011;29(38):6472-84.

16. Gidengil CA, Parker AM, Zikmund-Fisher BJ. Trends in risk perceptions and vaccination intentions: a longitudinal study of the first year of the H1N1 pandemic. Am J Public Health. 2012;102(4):672-9.

17. Setbon M, Raude J. Factors in vaccination intention against the pandemic influenza A/H1N1. Eur J Public Health. 2010;20(5):490-4.

18. Korani MF. Assessment of seasonal flu immunization status among adult patients visiting alSharaee Primary Health Care Center in Makkahal-Mokarramah. Int J Med Sci Public Health. 2015;4:117-23.

19. Al-Khashan HI, Selim MA, Mishriky AM, Binsaeed AA. Meningitis and seasonal influenza vaccination coverage among military personnel in central Saudi Arabia. Saudi Med J. 2011;32(2):159-65.

20. Chen N, Zhou M, Dong X, Qu J, Gong F, Han Y, et al. Epidemiological and clinical characteristics of 99 cases of 2019 novel coronavirus pneumonia in Wuhan, China: a descriptive study. Lancet. 2020;395(10223):507-13.

21. Allington D, Duffy B, Wessely S, Dhavan N, Rubin J. Health-protective behaviour, social media usage and conspiracy belief during the COVID-19 public health emergency. Psychol Med. 2020:1-7.

22. Halpin C, Reid B. Attitudes and beliefs of healthcare workers about influenza vaccination. Nurs Older People. 2019;31(2):32-9.

23. Alsuhaibani M. Barriers and beliefs among health-care workers regarding seasonal influenza vaccine in Al-Qassim region, Saudi Arabia. Human Vaccines \& Immunotherapeutics. 2020;16(2):313-20.

24. Dempsey AF, Pyrznawoski J, Lockhart S, Barnard J, Campagna EJ, Garrett K, et al. Effect of a Health Care Professional Communication Training Intervention on Adolescent Human Papillomavirus Vaccination: A Cluster Randomized Clinical Trial. JAMA Pediatr. 2018;172(5):e180016.

25. MacDonald NE, Hesitancy SWGoV. Vaccine hesitancy: Definition, scope and determinants. Vaccine. 2015;33(34):4161-4.

26. Seale H, Heywood AE, McLaws ML, Ward KF, Lowbridge CP, Van D, et al. Why do I need it? I am not at risk! Public perceptions towards the pandemic (H1N1) 2009 vaccine. BMC Infect Dis. 2010;10:99.

27. Biddlestone M, Green R, Douglas KM. Cultural orientation, power, belief in conspiracy theories, and intentions to reduce the spread of COVID-19. Br J Soc Psychol. 2020. 
28. Georgiou N, Delfabbro P, Balzan R. COVID-19-related conspiracy beliefs and their relationship with perceived stress and pre-existing conspiracy beliefs. Pers Individ Dif. 2020;166:110201.

29. van Prooijen JW, Douglas KM. Conspiracy theories as part of history: The role of societal crisis situations. Mem Stud. 2017;10(3):323-33.

30. Bangerter A, Krings F, Mouton A, Gilles I, Green EG, Clemence A. Longitudinal investigation of public trust in institutions relative to the 2009 H1N1 pandemic in Switzerland. PloS one. 2012;7(11):e49806.

31. Quinn SC, Kumar S, Freimuth VS, Kidwell K, Musa D. Public willingness to take a vaccine or drug under Emergency Use Authorization during the 2009 H1N1 pandemic. Biosecur Bioterror. 2009;7(3):275-90.

32. Maurer J, Uscher-Pines L, Harris KM. Perceived seriousness of seasonal and A(H1N1) influenzas, attitudes toward vaccination, and vaccine uptake among U.S. adults: does the source of information matter? Prev Med. 2010;51(2):185-7.

33. Fadda $M$, Albanese $E$, Suggs LS. When a COVID-19 vaccine is ready, will we all be ready for it? Int $J$ Public Health. 2020.

\section{Supplementary Files}

This is a list of supplementary files associated with this preprint. Click to download.

- graphicabstract.tiff

- Supplement.docx 